Article

\title{
Ba-Doped Iron Oxide as a New Material for $\mathrm{NO}_{2}$ Detection
}

\author{
Christian Lopez ${ }^{\text {, Chiara Baroni }}{ }^{2}$ and Jean-Marc Tulliani ${ }^{2, *}$
}

1 Laboratory of Electrochemistry and Physical-chemistry of Materials and Interfaces, UMR 5279, CNRS-Grenoble INP-Université de Savoie-Université Joseph Fourier, BP75, 38402 Saint Martin d'Hères, France; E-Mail: christian.lopez@lepmi.grenoble-inp.fr

2 Department of Applied Science and Technology, Politecnico di Torino, INSTM Reference Laboratory for Ceramics Engineering, Corso Duca degli Abruzzi 24, 10129 Torino, Italy; E-Mail: chiara.baroni@polito.it

* Author to whom correspondence should be addressed; E-Mail: jeanmarc.tulliani@polito.it; Tel.: +39-11-090-4700; Fax: +39-11-090-4624.

Received: 23 September 2013; in revised form: 5 October 2013 / Accepted: 16 October 2013 / Published: 22 October 2013

\begin{abstract}
Various compositions of barium-doped hematite between pure hematite $\left(\alpha-\mathrm{Fe}_{2} \mathrm{O}_{3}\right)$ and pure barium hexaferrite $\left(\mathrm{BaFe}_{12} \mathrm{O}_{19}\right)$ were synthesized by solid state reaction. The XRD analyses confirmed the progressive evolution of the two crystalline phases. Tests as humidity sensors show that the electrical resistance of samples containing high proportions of hexaferrite phase is strongly influenced. Electrochemical impedance spectroscopy (EIS) analyses under air or argon revealed an intrinsic semiconducting behavior for hematite and samples doped with 3 and 4 wt \% equivalent $\mathrm{BaO}$. The samples containing higher proportions of barium exhibited an extrinsic semiconducting behavior characterized by a variation of the conductivity with the oxygen partial pressure. This study allowed us to define the percolation threshold of the barium hexaferrite crystalline phase in the hematite matrix. The value was estimated to hematite doped with $5 \mathrm{wt} \% \mathrm{BaO}$, i.e., 36 wt $\%$ of barium hexaferrite phase. EIS analyses under various $\mathrm{NO}_{2}$ partial pressures confirmed the sensitivity of these materials. The linearity of the response was particularly evident for the 5, 10 and $14 \mathrm{wt} \%$ samples.
\end{abstract}

Keywords: hematite; barium hexaferrite; $\mathrm{NO}_{2}$ detection; impedance measurements 


\section{Introduction}

Nitrogen oxides ( $\mathrm{NO}$ and $\mathrm{NO}_{2}: \mathrm{NO}_{x}$ ), released from combustion facilities and automobiles, are a main cause of air pollution. They are responsible for acid rains, photochemical smog and are also potentially eutrophying agents, i.e., can cause an oversupply of nutrient in soils and water bodies. Therefore, they are known to be harmful to the environment, to people, and also to historical monuments and buildings. The current directive 2008/50/EC of the European Union and the future Decision 2011/850/EU (from 1 January 2014) on ambient air quality has set at $40 \mu \mathrm{g} / \mathrm{m}^{3}$ the annual limit value, and at $200 \mu \mathrm{g} / \mathrm{m}^{3}$ the hourly limit value, not to be exceeded more than 18 times in a calendar year, for the protection of human health against the effects of gaseous $\mathrm{NO}_{2}[1,2]$. Therefore, reliable, simple, effective and low-cost methods to monitor them have been highly demanded for atmospheric environmental measurements and controls.

Many of the systems usually employed for the monitoring of air pollutants are based on traditional photometric techniques like chemiluminescence [1], even if, more recently, electroanalysis techniques (amperometric approach), have been proposed and tested [3]. The main drawbacks associated to these techniques are represented by the use of expensive bench scale laboratory equipment including calibrating facilities.

Semiconducting metal oxide (SMO) sensors are one of the most widely studied groups of chemiresistive gas sensors due to their unique advantages such as low cost, small size, measurement simplicity, durability, ease of fabrication, and low detection limits ( $<$ ppm levels) [3]. Moreover, most SMO based sensors tend to be long-lived and somewhat resistant to poisoning [3]. The SMO undergoes reduction or oxidation while reacting with the target gas and this process causes an exchange of electrons at a certain characteristic rate, thereby affecting the sensor's resistance and yielding a certain signal [3].

Concerning the sensing materials for $\mathrm{NO}_{2}$ detection, tungsten oxide based materials have received a great attention in the last two decades. For example, pure and doped with various metal oxides $\mathrm{WO}_{3}$ sensors have been used as potential $\mathrm{NO}_{x}$ sensors [3]. $\mathrm{WO}_{3}$-based sensors produced by screen-printing can be highly responsive to $\mathrm{NO}_{2}$ down to $1 \mathrm{ppm}$, when operated at $250{ }^{\circ} \mathrm{C}$ [4]. $\mathrm{WO}_{3}$ thick films fired at $700{ }^{\circ} \mathrm{C}$ in $\mathrm{Ar} / \mathrm{O}_{2}$ flow have also proved to be operated at $100^{\circ} \mathrm{C}$ with excellent properties, such as fast response times, saturated stable sensitivity and rapid recovery characteristics to $\mathrm{NO}_{2}$ gas in air [5]. $\mathrm{WO}_{3}$-based nanocrystalline (3.0-9.0 nm size) thick films sensors with $\mathrm{TiO}_{2}$, can be used successfully for detecting and monitoring of $\mathrm{NO}_{2}$ in exhaust gases in parts per million level at $350{ }^{\circ} \mathrm{C}$ [6]. Zinc oxide thin and thick films have been also extensively studied for more than two decades. Several methods have been used to fabricate $\mathrm{ZnO}$ films and also their physical properties depend greatly on the method and condition of deposition [7]. Screen-printed $\mathrm{ZnO}, \mathrm{SnO}_{2}$ and $\mathrm{Sb}_{2} \mathrm{O}_{3}$ thick-films sensors sintered at 800,1000 and $1200{ }^{\circ} \mathrm{C}$ showed high sensitivity and excellent selectivity for ppm levels of $\mathrm{NO}_{2}$ gas [8]. Very recently, hybrid $\mathrm{ZnO}$ tetrapods + titanyl phthalocyanine exhibited a high sensor response $\left(\frac{\Delta R}{R_{\text {air }}} \approx 56\right.$ ) under $100 \mathrm{ppb}$ of $\mathrm{NO}_{2}$ at room temperature, but with slow response and recovery times (several tens of minutes) [9]. In contrast, monocrystalline $\mathrm{SnO}_{2}$ nanowires were sensitive in the range 18.9-1000 ppm of $\mathrm{NO}_{2}$ at $250{ }^{\circ} \mathrm{C}$ with fast response and recovery times of $7 \mathrm{~s}$ and $8 \mathrm{~s}$, respectively [10]. Gas sensors based on indium oxide nanowires, $\operatorname{In}_{2} \mathrm{O}_{3}$ or $\operatorname{In}_{x} \mathrm{O}_{y} \mathrm{~N}_{z}$ films grown by the 
metal organic CVD technique also showed good selectivity to $\mathrm{NO}_{2}$ with little interference from other gases $[11,12]$. In addition, Indium Tin Oxide (ITO) thin films were found to exhibit high sensitivity toward $\mathrm{NO}_{2}$ and $\mathrm{NO}$ associated to a good selectivity with respect to $\mathrm{CO}$ and $\mathrm{CH}_{4}$ [12]. $\mathrm{TeO}_{2}$ thin films proved to be effective in $\mathrm{NO}_{2}$ detection in the range of 1-120 ppm too [13]. The results showed the best sensitivity to $\mathrm{NO}_{2}$ at room temperature, but with a response time of about 6 min for 1 ppm to about $1.2 \mathrm{~min}$ for $120 \mathrm{ppm} \mathrm{NO} 2$ concentration and longer recovery times.

Carbon nanotubes [14], YSZ [15], $\mathrm{SnO}_{2}, \mathrm{Nb}$ or $\mathrm{In}_{2} \mathrm{O}_{3}$ doped hematite [16,17] have been also proposed for $\mathrm{NO}_{2}$ detection. Alkaline or earthy-alkaline-doped hematite $\left(\alpha-\mathrm{Fe}_{2} \mathrm{O}_{3}\right)$ materials have been investigated recently in the literature, as $\mathrm{NO}_{x}$ sensors [18] and $5 \mathrm{wt} \% \mathrm{BaO}$ addition to hematite seemed to lead to a promising sensing material. Therefore, the aim of this work is to study in more detail barium-doped hematite as an electrochemical sensor for $\mathrm{NO}_{2}$ detection.

\section{Experimental Section}

$\alpha-\mathrm{Fe}_{2} \mathrm{O}_{3}$ powder (Aldrich $>99 \%$, particle size distribution below $2 \mathrm{~m}$ ) was mixed in ethanol with barium nitrate used as precursor of 3, 4, 5, 10 and $14 \mathrm{wt} \%$ equivalent of barium oxide respect to hematite (Fluka $>99 \%$ ), until stoichiometrical composition of $\mathrm{BaFe}_{12} \mathrm{O}_{19}$, in a planetary mill for $1 \mathrm{~h}$. After drying overnight, the mixtures were uniaxially pressed at $370 \mathrm{MPa}$ and calcined at $900{ }^{\circ} \mathrm{C}$ for $1 \mathrm{~h}$. These samples were then planetary milled for $6 \mathrm{~h}$ in ethanol with polyethylene glycol (PEG 4000, Sigma-Aldrich, Milan, Italy) to increase the densities of the different samples. After drying overnight, the powders were ready to use. The grain size of the produced powders was then determined by means of a laser granulometre (Fritsch analysette 22). The different mixtures of Ba-doped $\alpha-\mathrm{Fe}_{2} \mathrm{O}_{3}$ were pressed ad $370 \mathrm{MPa}$ again and sintered at $1300{ }^{\circ} \mathrm{C}$ for $1 \mathrm{~h}$.

Geometrical density evolution in function of percentage of added barium oxide was studied and the samples were characterized by X-ray diffraction (PW1710, Philips Eindhoven, The Netherland), in the $5^{\circ}-70^{\circ} 2$ theta range, after calcination at $900{ }^{\circ} \mathrm{C}$ and sintering at $1300{ }^{\circ} \mathrm{C}$. The pellets were also observed by means of a scanning electron microscope (SEM, S2300, Hitachi Tokyo, Japan).

Interdigitated gold electrodes (ESL 520A) were screen-printed onto the surface of the pellets of hematite and doped hematite fired at $1300{ }^{\circ} \mathrm{C}$ and the sensors humidity response was studied in the range $0 \%-100 \%$ relative humidity $(\mathrm{RH})$ because it is known in the literature that water molecules can interfere in gas detection, both with respect to adsorption of other species and to surface catalysis $[19,20]$. In a chamber, compressed air was separated into two fluxes: one was dehydrated over a chromatography alumina bed, while the second one was directed through two water bubblers, generating, respectively, a dry and a humid flow. Two precision microvalves allowed to recombine the two fluxes into one by means of a mixer and to adjust the RH content while keeping constant the testing conditions, in particular a flow rate of $0.05 \mathrm{~L} / \mathrm{s}$. The relative humidity was not increased in a continuous mode but was varied by steps every $3 \mathrm{~min}$. The measurements were performed at room temperature. A commercial humidity and temperature probe was used as a reference for temperature and RH values (Delta Ohm HD2101.1), accuracy: $\pm 0.1 \%$ in the $0 \%-100 \%$ RH range and $-50-250{ }^{\circ} \mathrm{C}$ temperature range. Each tested sensor was alimented by an external alternating voltage $(V=3.6 \mathrm{~V}$ at the rate of $1 \mathrm{kHz}$ ) and then constituted a variable resistance of this electrical circuit. A multimeter (Keithley 2000) was used to measure the tension $V_{D C}$ at the output of the circuit. The sensor resistance 
was determined by substituting them, in the circuit, by known resistances and then plotting a calibrating curve $R=f\left(V_{D C}\right)$ [21,22].

The electrical behavior of the materials was studied by AC impedance spectroscopy (4192A LF Impedance Analyzer, Hewlett Packard, Palo Alto, CA, USA) after painting platinum electrodes (ESL 5545, Electro-Science Laboratories, King of Prussia, PA, USA) onto the two faces of the pellets $(1 \mathrm{~cm}$ in diameter and $1 \mathrm{~mm}$ in thickness). The measurements were performed in a furnace under dry synthetic air (Messer air 80/20) and argon (Messer argon 5.0), between 100 and $700{ }^{\circ} \mathrm{C}$, in the $5 \mathrm{~Hz}-13 \mathrm{MHz}$ frequency range. Excitation voltage was fixed at $100 \mathrm{mV}$. The previous samples were also studied under $\mathrm{NO}_{2}$. AC impedance measurements were performed in a mixed flux of helium (Messer 4.6) and nitrogen dioxide (Messer $1000 \mathrm{ppm} \mathrm{NO}_{2} 1.8$ in $\mathrm{N}_{2}$ 5.0) under a constant flow rate of $40 \mathrm{~mL} / \mathrm{min}$ and a $0-500 \mathrm{ppm}$ range $\mathrm{NO}_{2}$ concentration. Excitation voltage was fixed at $100 \mathrm{mV}$ in the $5 \mathrm{~Hz}-13 \mathrm{MHz}$ frequency range.

Sensor response $(S R)$ was calculated from impedance measurements considering the resistance at $1000 \mathrm{~Hz} . \mathrm{SR}$ is a function of $\mathrm{NO}_{2}$ concentration and is determined as follows [23] (Equation (1)):

$$
S R=\frac{R_{(P g a s)}-R_{(P g a s \rightarrow 0)}}{R_{(P g a s \rightarrow 0)}}
$$

$R_{(\text {Pgas })}$ represents the value of resistance in presence of the gas studied $\left(\mathrm{NO}_{2}\right.$ in the present case) and $R_{(\text {Pgas } \rightarrow 0)}$ the resistance without this gas.

\section{Results and Discussion}

\subsection{Microstructure}

After the first thermal treatment at $900{ }^{\circ} \mathrm{C}$ and the $6 \mathrm{~h}$ planetary milling, the powders showed a mean diameter of $3.40 \mu \mathrm{m}$ for 3, 4, 5 and $10 \mathrm{wt} \%$ equivalent of Ba-doped hematite samples, and of $9.00 \mu \mathrm{m}$ for $14 \mathrm{wt} \%$ of $\mathrm{Ba}$-doped hematite. These values are comparable to the mean diameter of the starting $\alpha-\mathrm{Fe}_{2} \mathrm{O}_{3}$ powder $(2 \mu \mathrm{m})$. X-ray diffraction patterns of the Ba-doped hematite after the first thermal treatment at $900{ }^{\circ} \mathrm{C}$ for $1 \mathrm{~h}$ and sintering at $1300{ }^{\circ} \mathrm{C}$, confirmed the presence of two crystalline phases in all the samples: hematite (JCPDS card n.33-0664) and barium hexaferrite, $\mathrm{BaFe}_{12} \mathrm{O}_{19}$ (JCPDS card n.39-1433). As expected, we observe (Figure 1) the intensity of the barium hexaferrite peaks increasing with $\mathrm{BaO}$ additions from the pure hematite sample $(\mathrm{H})$ to the pure barium hexaferrite sample (14\% BA i.e., $\left.\alpha-\mathrm{Fe}_{2} \mathrm{O}_{3}+14 \mathrm{wt} \% \mathrm{BaO}\right)$.

Table 1 summarizes the six compositions studied in the present work. Theoretical densities were calculated considering that in all the mixtures the barium oxide was completely transformed into barium hexaferrite crystalline phase by reaction with hematite. The densities increase with increasing the sintering temperature (Figure 2a) but also decrease with barium oxide content (Figure $2 \mathrm{~b}$ ).

Figure 3 illustrates the microstructures of pure hematite, 3\% BA, 4\% BA, 5\% BA, 10\% BA and $14 \%$ BA samples: the rather high densities of the materials fired at $1300{ }^{\circ} \mathrm{C}$ are confirmed. In the Ba-doped hematite samples, two different microstructures are present: a first one showing hexagonal grains, characteristic of hematite, and a second one characterized by lamellar grains, corresponding to the $\mathrm{BaFe}_{12} \mathrm{O}_{19}$ phase. 
Figure 1. XRD spectra of various barium-doped hematite samples.

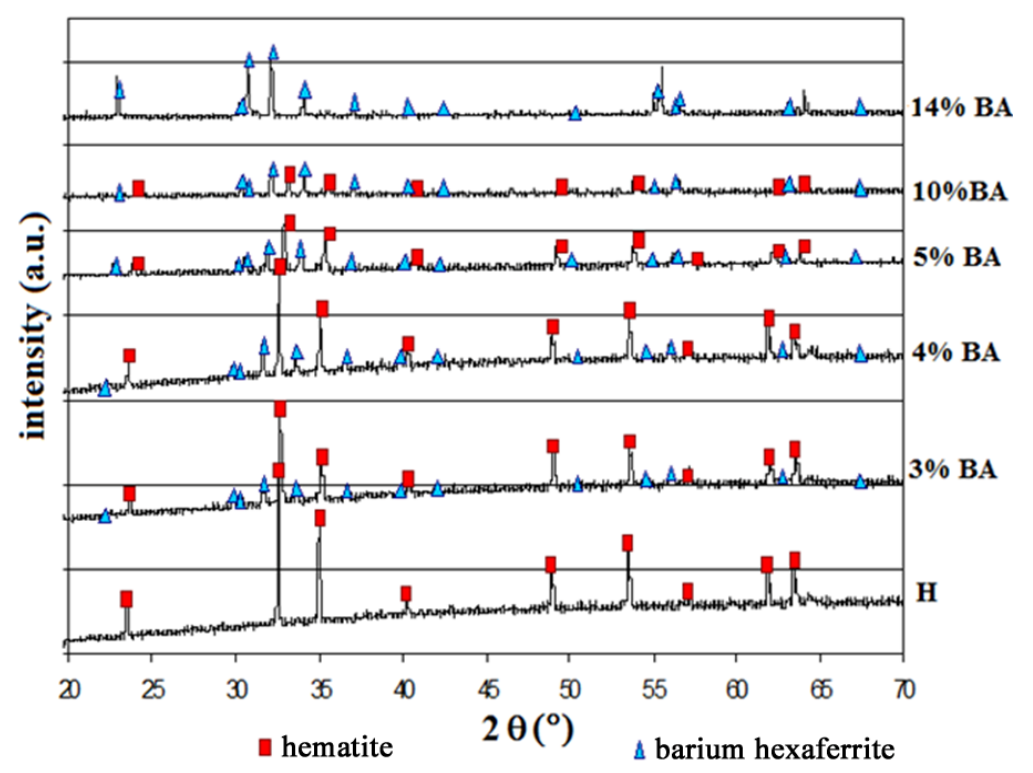

Table 1. Density of the barium-doped hematite pellets with polyethylene glycol (PEG) addition.

\begin{tabular}{cccc}
\hline Label & Sample & ${\left.\text { Expected } \mathbf{B a F e}_{\mathbf{1 2}} \mathbf{O}_{\mathbf{1 9}} \mathbf{( w t} \%\right)}^{\text {Relative density (\%) }}$ \\
\hline $\mathrm{H}$ & $\alpha-\mathrm{Fe}_{2} \mathrm{O}_{3}$ & 0 & 96.9 \\
$3 \% \mathrm{BA}$ & $\alpha-\mathrm{Fe}_{2} \mathrm{O}_{3}+3 \mathrm{wt} \% \mathrm{BaO}$ fired at $1300^{\circ} \mathrm{C}$ & 18.12 & 95.2 \\
$4 \% \mathrm{BA}$ & $\alpha-\mathrm{Fe}_{2} \mathrm{O}_{3}+4 \mathrm{wt} \% \mathrm{BaO}$ fired at $1300^{\circ} \mathrm{C}$ & 21.75 & 94.8 \\
$5 \% \mathrm{BA}$ & $\alpha-\mathrm{Fe}_{2} \mathrm{O}_{3}+5 \mathrm{wt} \% \mathrm{BaO}$ fired at $1300{ }^{\circ} \mathrm{C}$ & 36.24 & 94.8 \\
$10 \% \mathrm{BA}$ & $\alpha-\mathrm{Fe}_{2} \mathrm{O}_{3}+10 \mathrm{wt} \% \mathrm{BaO}$ fired at $1300{ }^{\circ} \mathrm{C}$ & 72.48 & 93.1 \\
$14 \% \mathrm{BA}$ & $\alpha-\mathrm{Fe}_{2} \mathrm{O}_{3}+14 \mathrm{wt} \% \mathrm{BaO}$ fired at $1300^{\circ} \mathrm{C}$ & 100.00 & 92.0 \\
\hline
\end{tabular}

The grain sizes are rather different between the various samples (Figure 3): the grain size decrease when increasing barium hexaferrite content until 10\% BA.

Figure 2. Geometrical density evolutions: (a) with temperature for 5\% BA; (b) with barium oxide content for samples fired at $1300^{\circ} \mathrm{C}$.
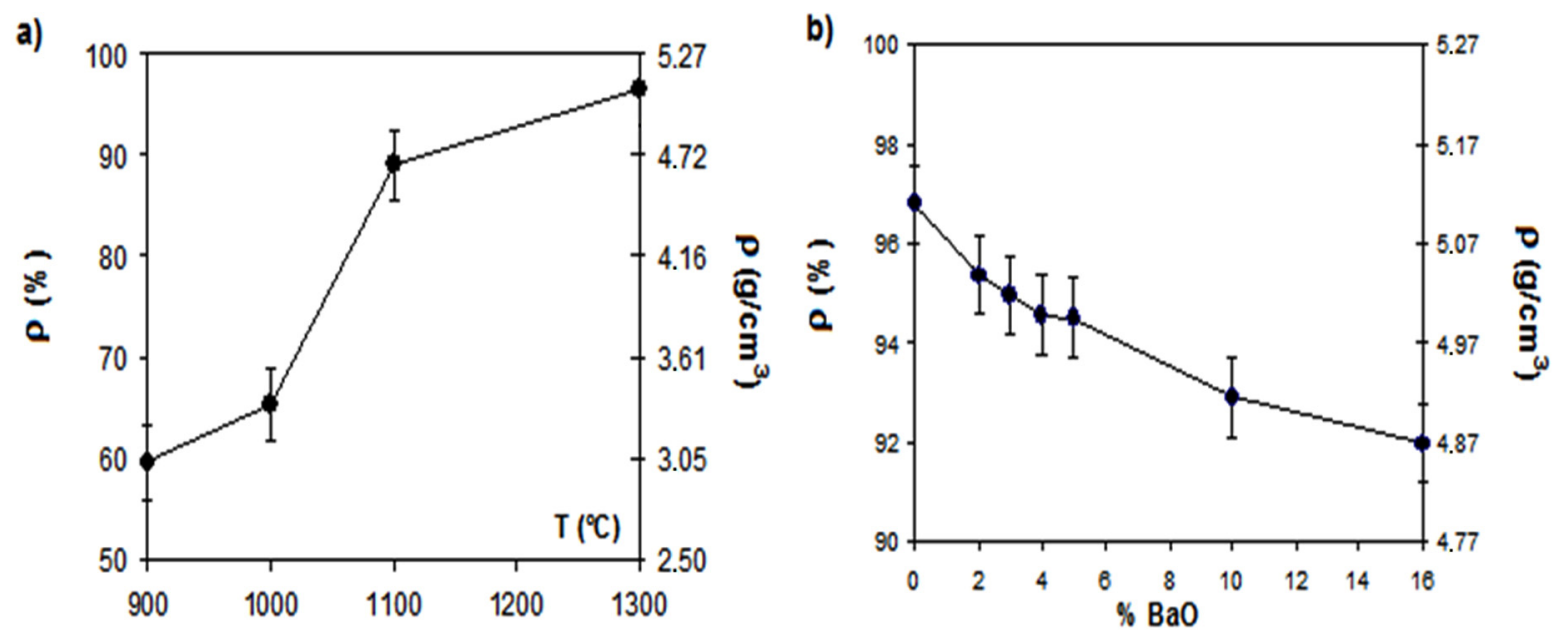
Figure 3. SEM micrographs of sintered samples: (a) H (1000×); (b) 3\% BA (1000×); (c) 4\% BA $(1000 \times)$; (d) 5\% BA $(2000 \times)$; (e) 10\% BA (2000×); (f) 14\% BA (1000×).
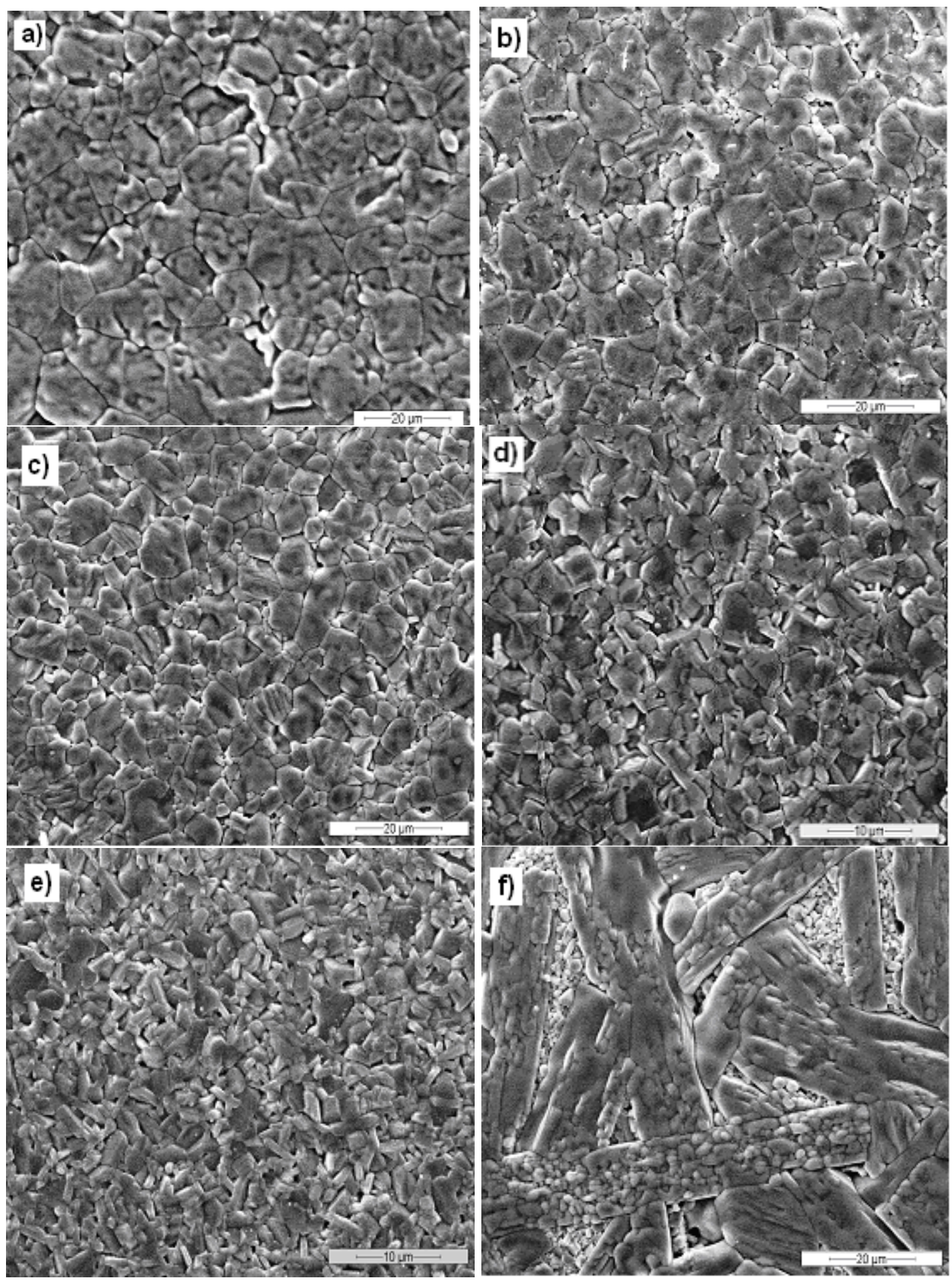

\subsection{Humidity Sensitivity}

The correlation between humidity sensor response and the material porosity is known in the literature, and it is possible to evaluate the pore radius at which capillary condensation occurs at different temperatures ( $T$ ) by means of the Kelvin equation [19] (Equation (2)): 


$$
r_{k}=\frac{2 \gamma M}{\rho R T \ln \left(\frac{P}{P_{S}}\right)}
$$

where $r_{k}$ is pore radius; $M$ are respectively the water surface tension, density and molecular weight, while $P$ and $P s$ are the water vapor pressures in the surrounding atmosphere and at saturation, respectively.

Because the porous structure of ceramics with open pores tends to favor water and gases adsorption and condensation, and though, on semiconducting materials these features are less critical [24], the efforts were oriented on the reduction of the sample porosity, as in general, dense ceramics show negligible humidity-sensitivity [25].

The retained solution was to increase the green density of the pellets by adding polyethylene glycol (PEG 4000) to the doped powder, during the $6 \mathrm{~h}$ planetary milling step and prior to uniaxial pressing. The samples were then sintered at $1300{ }^{\circ} \mathrm{C}$ and characterized like the previous ones. A significant increase of the density was then observed after PEG addition and sintering on the 5\% BA composition (Table 2).

Interdigitated gold electrodes were screen-printed on the surface of the different samples and the sensors humidity responses were studied in the range $0 \%-100 \%$ relative humidity $(\mathrm{RH})$ at $20{ }^{\circ} \mathrm{C}$. Humidity measurements were realized every three minutes.

As an illustration of the influence of density regarding the humidity sensitivity the electrical response of the 5\% BA samples with and without PEG 4000 under water vapor (Figure 4) shows that the pellet with PEG $(R=1400 \Omega)$ is quite insensitive to humidity. This result validates our choice to increase the density of the samples if we consider humidity as an interfering gas regarding nitrogen dioxide sensitivity.

Table 2. Density of the $5 \mathrm{wt} \%$ barium-doped hematite pellets with and without PEG addition.

\begin{tabular}{ccc}
\hline Sample & Geometrical density $\left(\mathbf{g} / \mathbf{c m}^{\mathbf{3}}\right)$ & Relative density (\%) \\
\hline 5\% BA & $4.32 \pm 0.05$ & 83.0 \\
$5 \%$ BA + PEG 4000 & $5.08 \pm 0.05$ & 95.0 \\
\hline
\end{tabular}

Figure 4. Humidity sensors (5\% BA) response after 3 min of valve switch in function of $\mathrm{RH}$, at $20^{\circ} \mathrm{C}$, for the samples fired at $1300^{\circ} \mathrm{C}$, with and without PEG 4000 addition.

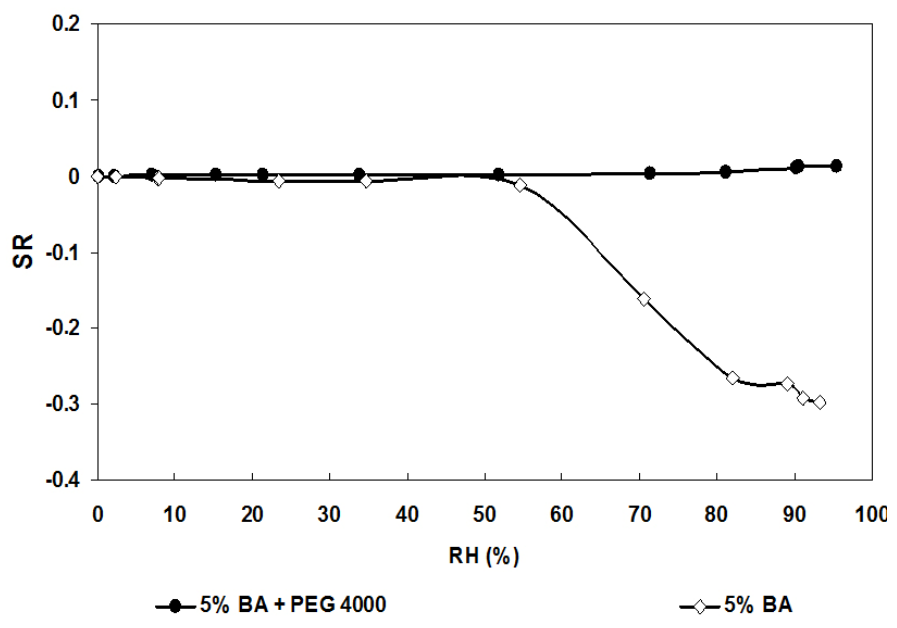


Subsequently, all the samples responses were characterized under humidity (Figure 5) at room temperature. They show no sensitivity to water vapor, with the exception of the $10 \% \mathrm{BA}$ sample which exhibits a slightly increase of the SR above $70 \mathrm{RH} \%$ and the $14 \%$ BA sample for which an increase of the sensor response (negative values) is evidenced above $35 \mathrm{RH} \%$.

\subsection{Electrical Study}

Impedance measurements were performed in dry synthetic air $\left(20 \% \mathrm{O}_{2}\right)$ and under argon $(<2$ ppm $\mathrm{O}_{2}$ ), between 100 and $700{ }^{\circ} \mathrm{C}$, in the $5 \mathrm{~Hz}-13 \mathrm{MHz}$ frequency range.

The conductivities evolutions in Arrhenius representations of pure hematite and the 5 compositions of barium-doped hematite samples showed that the samples behaved as semiconductors. Figure 6 shows two types of electrical behaviors. Pure hematite as well as 3\% BA and 4\% BA samples present a linear dependence of the conductivity with superimposition of the measurements under air and argon.

The n-type semiconductor behavior of hematite is clearly reported in literature [26]. Oxygen vacancies $\left(V_{O}^{\bullet \bullet}\right)$ can be produced by heating this material following the disorder Equation (3) [27]:

$$
O_{O}^{X}=\frac{1}{2} O_{2(g)}+V_{O}^{\bullet \bullet}+2 e^{\prime}
$$

Figure 5. Humidity sensors response of various barium-doped hematite samples, after 3 min of valve switch, in function of relative humidity $(\mathrm{RH})$, at $20^{\circ} \mathrm{C}$.

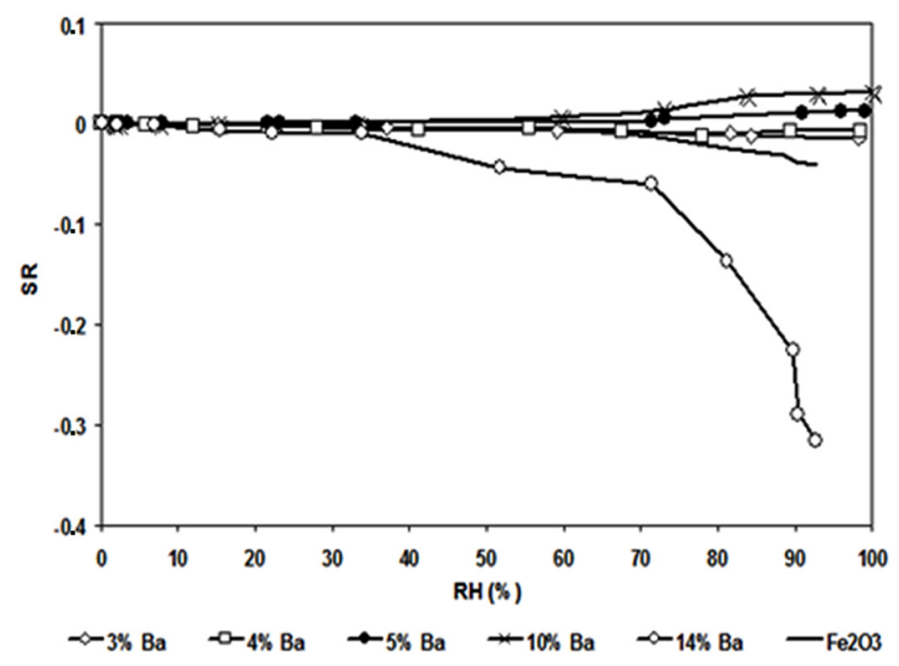

Gardner et al. [28] measured the oxygen deficit resulting from this equilibrium shift. Considering this structural disorder and the independence of the hematite conductivity regarding the oxygen partial pressure shown in the Figure 6a, we can conclude that this material is an intrinsic semiconductor [27,29]. The large value of activation energy measured in this work (Table 3) is the consequence of our experimental procedure where samples were sintered at $1300{ }^{\circ} \mathrm{C}$ and cooled under air laboratory. Under those conditions, the oxygen vacancies created during the heat treatment disappear by re-oxidation [28] and hematite becomes a slight n-type semiconductor [30]. The value of $0.71 \mathrm{eV}$ obtained in the present work is close to the one reported by Gardner [28]. 
Table 3. Activation energies calculated from the linear regions of the Figure 6.

\begin{tabular}{|c|c|c|c|c|}
\hline \multirow{3}{*}{ Sample } & \multicolumn{4}{|c|}{ Activation Energy (eV) } \\
\hline & \multicolumn{2}{|c|}{ Below $500^{\circ} \mathrm{C}$} & \multicolumn{2}{|c|}{ Above $500^{\circ} \mathrm{C}$} \\
\hline & Argon & Air & Argon & Air \\
\hline $\mathrm{H}$ & & & & \\
\hline $3 \% \mathrm{BA}$ & & & & \\
\hline $4 \% \mathrm{BA}$ & & & & \\
\hline $5 \% \mathrm{BA}$ & 0.36 & 0.51 & & \\
\hline $10 \% \mathrm{BA}$ & 0.35 & 0.40 & & \\
\hline $14 \% \mathrm{BA}$ & 0.43 & 0.52 & & \\
\hline
\end{tabular}

Figure 6. Arrhenius plots in air and argon of samples: (a) H; (b) 3\% BA; (c) 4\% BA; (d) $5 \% \mathrm{BA}$; (e) $10 \% \mathrm{BA}$; (f) $14 \% \mathrm{BA}$.
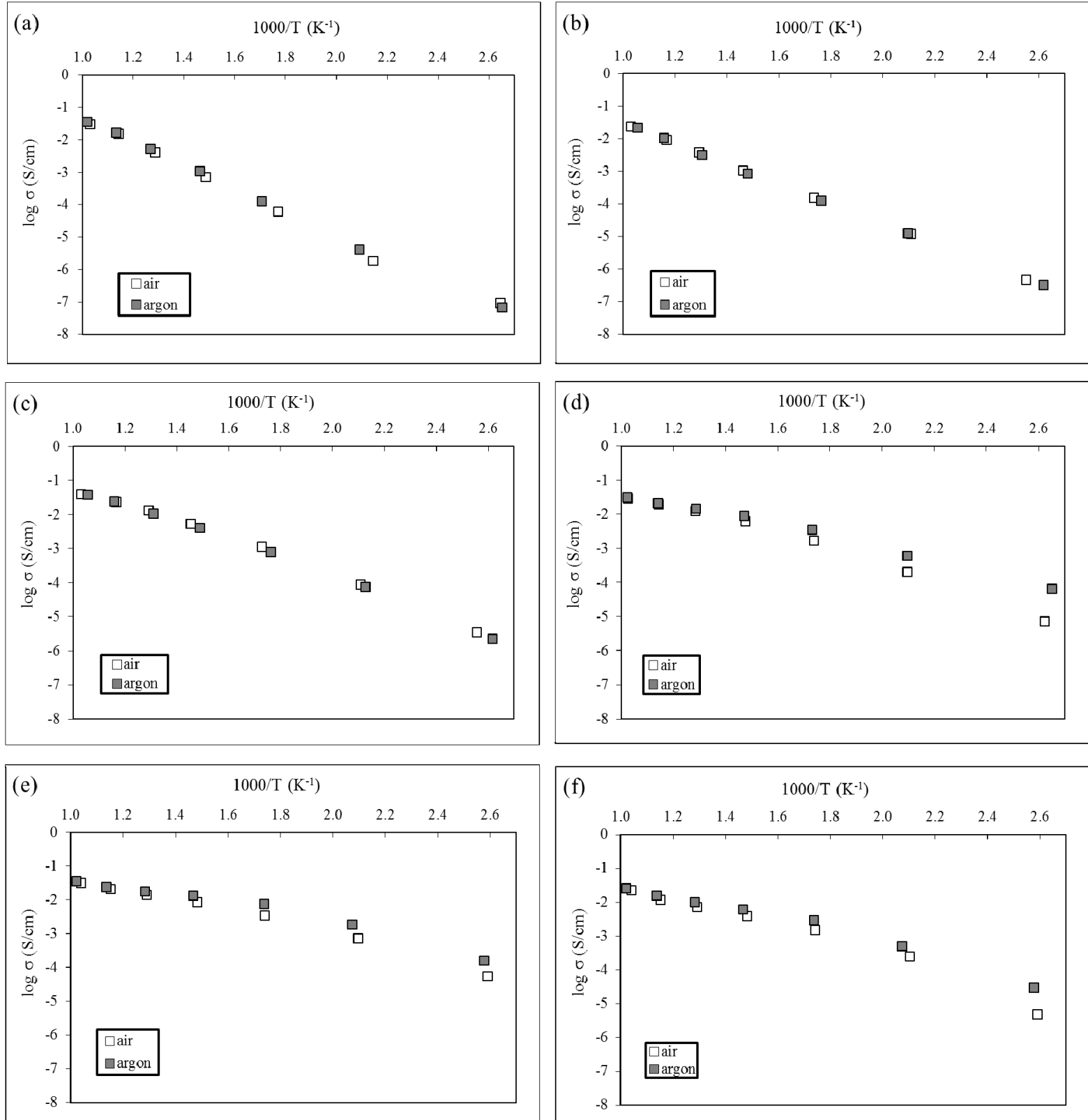
In the case of $5 \% \mathrm{BA}, 10 \% \mathrm{BA}$ and $14 \% \mathrm{BA}$ samples, the Figure 6 exhibits two linear regions, below and above $500{ }^{\circ} \mathrm{C}\left(1000 / \mathrm{T}=1.3 \mathrm{~K}^{-1}\right)$ : no influence of the oxygen partial pressure above $500{ }^{\circ} \mathrm{C}$ is observed, while a strong influence of the oxygen partial pressure below $500{ }^{\circ} \mathrm{C}$ is evidenced. The conductivities increase as the oxygen partial pressure decreases (the conductivities under argon are greater than the conductivities under air). This corresponds to the behavior of an n-type extrinsic semiconductor.

Kim et al. [27] suggested a doping process with reduction of a part of $\mathrm{Fe}$ (III) to $\mathrm{Fe}(\mathrm{II})$, oxygen vacancies formation and concentration increase of negative charge carriers (electrons). These authors measured the electrical conductivity of pure and $\mathrm{CdO}-\alpha-\mathrm{Fe}_{2} \mathrm{O}_{3}$ system with various mol $\%$ of $\mathrm{CdO}$ in the 300-1300 ${ }^{\circ} \mathrm{C}$ temperature range and $10^{-9}-10^{-1}$ atm oxygen partial pressure range. They also suggested that the semiconductivity became intrinsic for temperatures above $500{ }^{\circ} \mathrm{C}$. We observe the same phenomenon and the activation energies deduced from the Figure $6 \mathrm{~d}-\mathrm{f}$ are close to the values obtained by Gardner et al. [28] on pure hematite in the same temperature range $(0.1$ to $0.3 \mathrm{eV})$.

The increase of barium percentages in hematite is correlated with the increase of the conductivity for the different materials. It is particularly evident since we compare the Figure 6a,f. The XRD analyses presented earlier underlined the presence of two crystalline phases: $\alpha-\mathrm{Fe}_{2} \mathrm{O}_{3}$ (hematite) and $\mathrm{BaFe}_{12} \mathrm{O}_{19}$ (barium hexaferrite). If we consider that the Figure $6 \mathrm{a}$ represents the pure hematite electrical behavior and the Figure $6 \mathrm{f}$ the pure barium hexaferrite one, we can conclude that this latter phase is a better electronic conductor than the hematite phase. Considering now the intermediate compositions presented in the Figure $6 \mathrm{~b}-\mathrm{e}$, it is noticeable that the transition of electrical behavior observed between the Figures $6 \mathrm{c}$ and $6 \mathrm{~d}$ corresponds, respectively, to a composition transition between 21 to $36 \mathrm{wt} \%$ of the most conductive phase (barium hexaferrite) in the material. Therefore, for a composition below $36 \mathrm{wt} \%$ of barium hexaferrite, hematite is the main crystalline phase and the materials exhibit the intrinsic semiconducting behavior observed in the Figure $6 \mathrm{a}-\mathrm{c}$. The Figure $6 \mathrm{c}, \mathrm{d}$ define a percolation threshold of the barium hexaferrite crystalline phase in the hematite matrix. Thus, the materials which composition exceeds $36 \mathrm{wt} \%$ of this latter phase, exhibit the $\mathrm{n}$ type extrinsic semiconducting behavior observed on the Figure $6 \mathrm{~d}-\mathrm{f}$.

\section{4. $\mathrm{NO}_{2}$ Sensitivity}

The response to $\mathrm{NO}_{2}$ was investigated in a mixed flux of helium and $\mathrm{N}_{2} / \mathrm{NO}_{2}$ under a flow rate of $40 \mathrm{~mL} / \mathrm{min}\left(0-500 \mathrm{ppm}\right.$ of $\left.\mathrm{NO}_{2}\right)$, between 60 and $350{ }^{\circ} \mathrm{C}$, in the $5 \mathrm{~Hz}-13 \mathrm{MHz}$ frequency range. As an example, Figure 7 represents the evolution of impedance spectra regarding the $\mathrm{NO}_{2}$ partial pressure.

The gas composition clearly influences the low frequency impedance. Consequently the values of $S R$ were calculated from resistance measured at $1000 \mathrm{~Hz}$. Figure 8 represents the evolution of the $S R\left(P_{\mathrm{NO} 2}\right)$ of pure and doped hematite at $200{ }^{\circ} \mathrm{C}$. We observed that for temperatures above $300{ }^{\circ} \mathrm{C}$ most of the materials exhibited a poor $\mathrm{NO}_{2}$ sensitivity while for temperatures below $200{ }^{\circ} \mathrm{C}$ the impedance of most of them were too high (and also the uncertainties) to permit a quantitative determination of the resistance. Therefore, considering the highest sensitivity $S$ (slope of the representation $S R\left(P_{\mathrm{NO} 2}\right)$ gathered in the Table 4) and the lowest uncertainties, the optimal working temperature is estimated to $200{ }^{\circ} \mathrm{C}[16,31,32]$. 
Figure 7. Impedance spectra evolution of $5 \%$ BA sample at $200{ }^{\circ} \mathrm{C}$ for various nitrogen oxide partial pressures.

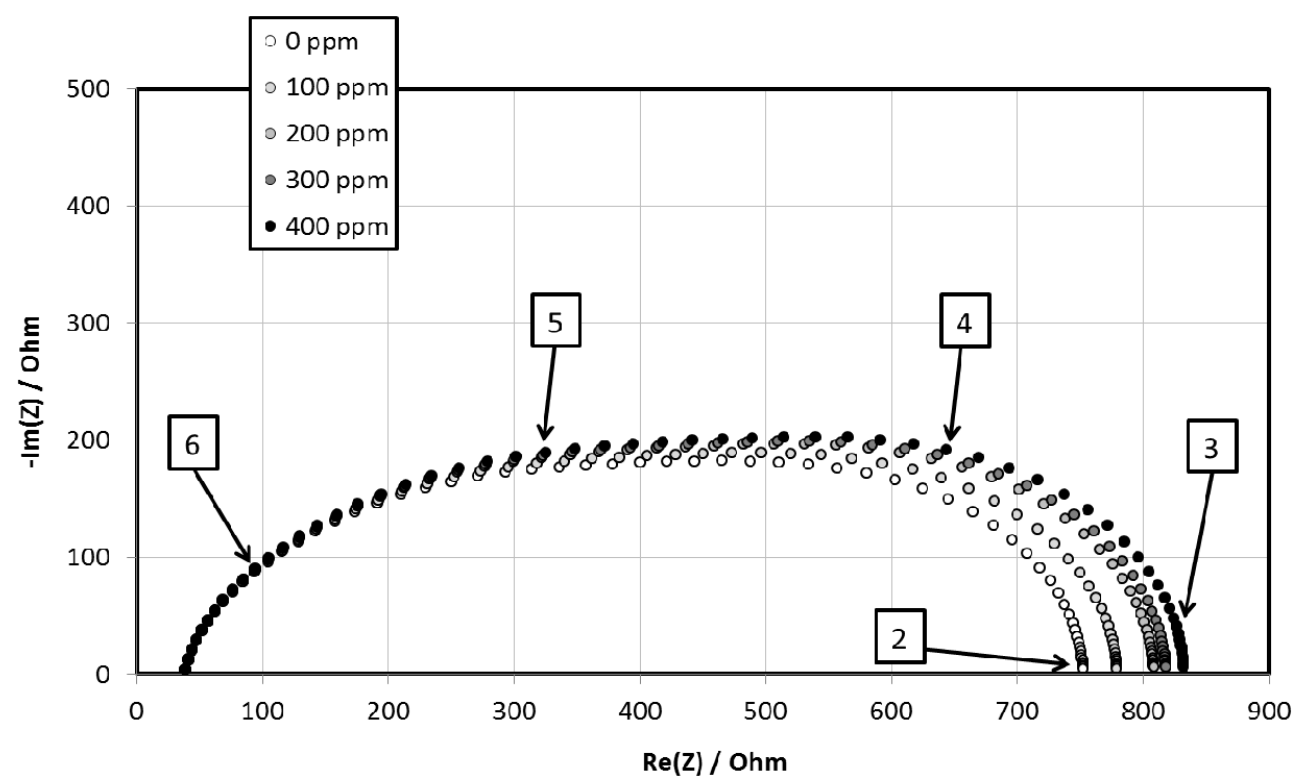

Table 4. Sensitivity $(S)$ of hematite and various barium-doped hematite pellets measured at $200{ }^{\circ} \mathrm{C}$.

\begin{tabular}{ccc}
\hline Sample & $\boldsymbol{S}\left(\mathbf{p p m}^{-\mathbf{1}}\right)$ & $\boldsymbol{R}\left(\boldsymbol{P}_{\mathbf{N O 2} \rightarrow \mathbf{0}}\right)(\mathbf{O h m})$ \\
\hline H & $0.95 \times 10^{-4}$ & 115,200 \\
$3 \%$ BA & $1.19 \times 10^{-4}$ & 11,485 \\
$4 \%$ BA & $1.00 \times 10^{-4}$ & 3943 \\
$5 \%$ BA & $2.86 \times 10^{-4}$ & 747 \\
$10 \%$ BA & $3.67 \times 10^{-5}$ & 695 \\
$14 \%$ BA & $6.06 \times 10^{-4}$ & 380 \\
\hline
\end{tabular}

In the continuously regenerating diesel particulate filter (CRDPF) technology, $\mathrm{NO}_{2}$ is used to combust the soot collected in a particulate filter because it is a stronger oxidant than $\mathrm{O}_{2}$, promoting low temperature oxidation of soot in the range $200-500{ }^{\circ} \mathrm{C}$ [33]. This oxidation of carbon by $\mathrm{NO}_{2}$ is then achievable under normal driving conditions, particularly in heavy duty engine applications [34]. However, typically, $\mathrm{NO}_{2}$ is $5 \%$ to $15 \%$ of the total $\mathrm{NO}_{x}$ in the diesel exhaust, but oxidation catalysts like Pt could oxidize $\mathrm{NO}$ to $\mathrm{NO}_{2}$ increasing $\mathrm{NO}_{2}$ concentrations to $50 \%$ of the total $\mathrm{NO}_{x}$, in the temperature range of $300-350{ }^{\circ} \mathrm{C}$ [33]. Then, emissions of $\mathrm{NO}_{x}$ can be higher than $300 \mathrm{ppm}[33,34]$, in function of the driving conditions, therefore, the materials studied in this work could be proposed as potential $\mathrm{NO}_{x}$ sensors for diesel exhaust gases.

All the materials present a resistance increase with the $\mathrm{NO}_{2}$ partial pressure. This result has already been observed with hematite and various ferrites [16,32,35]. The 3\% BA and 4\% BA samples (Figure $8 \mathrm{~b}, \mathrm{c}$ ) exhibit a SR evolution close to the pure hematite one (Figure $8 \mathrm{a}$ ). Such a similarity was observed in the electrical study reported in the present paper. Otherwise, the Figure $8 \mathrm{~d}-\mathrm{f}$ show that beyond the percolation threshold described previously, the sensitivity to $\mathrm{NO}_{2}$ increases with the barium hexaferrite content in the sample. Nevertheless, considering the results of humidity sensitivity 
presented in the present paper the 5\% BA sample seems to be the best compromise regarding the highest $\mathrm{NO}_{2}$ sensitivity with the lowest humidity interference.

Figure 8. Sensor response (SR) evolution at $200{ }^{\circ} \mathrm{C}$ on the samples (a) H; (b) $3 \% \mathrm{BA}$; (c) $4 \% \mathrm{BA}$; (d) $5 \% \mathrm{BA}$; (e) 10\% BA; (f) $14 \% \mathrm{BA}$ in $0-500 \mathrm{ppm} \mathrm{NO}_{2}$. Resistance measured at $1000 \mathrm{~Hz}$.
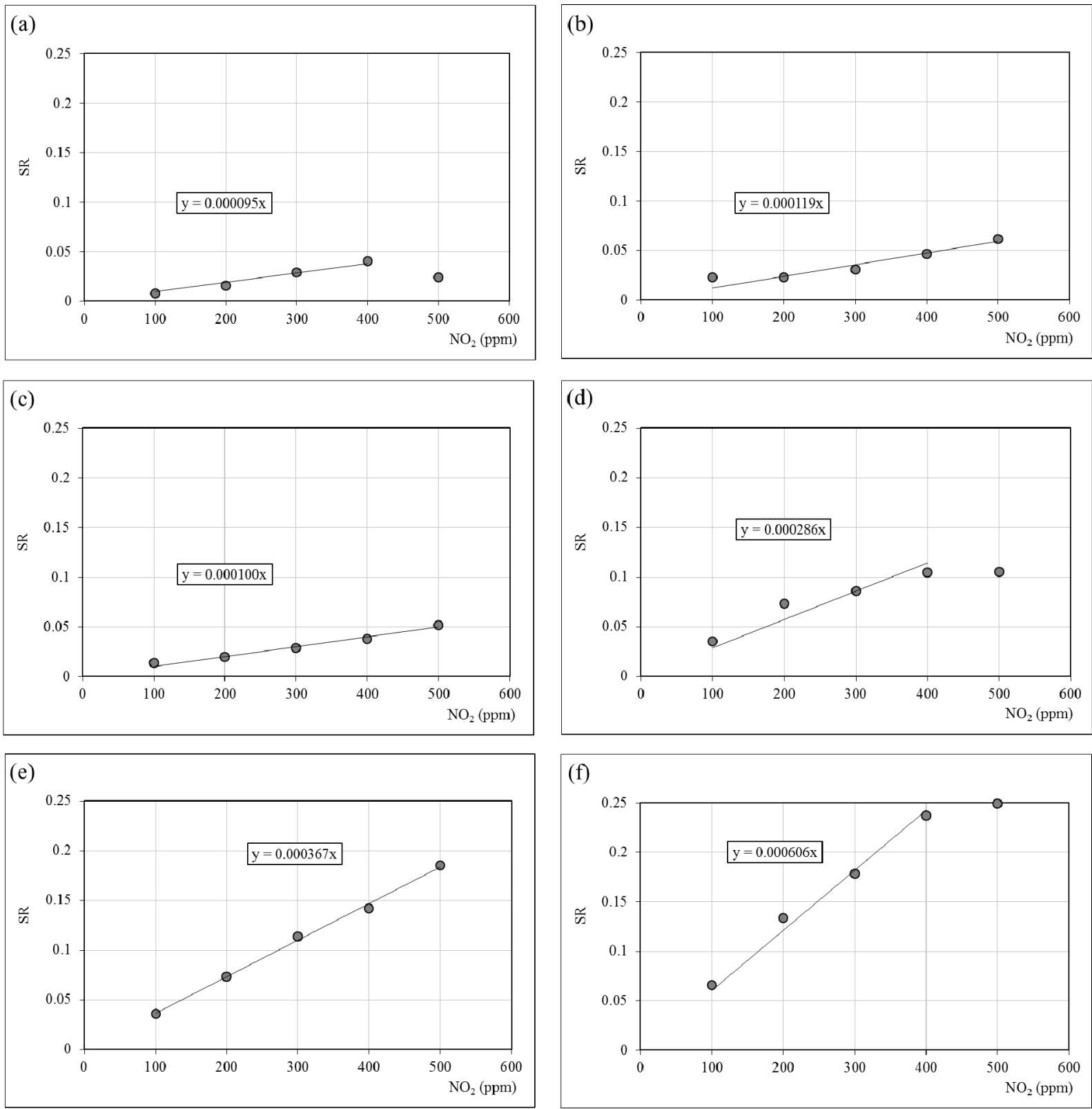

In an n-type semiconductor, $\mathrm{NO}_{2}$ does not react with pre-adsorbed oxygen and resistance changes occur by a direct chemisorption process [36]. A series of reactions (Equations (4)-(8)) giving nitrates and nitrites is proposed in reference [37]:

$$
\begin{gathered}
\mathrm{NO}_{2}+\mathrm{e}^{-} \text {(c.b.) } \leftrightarrow \mathrm{NO}_{2}^{-} \\
\mathrm{NO}_{2}+\mathrm{V}_{\mathrm{O}}^{+} \leftrightarrow \mathrm{NO}_{2}^{-}+\mathrm{V}_{\mathrm{O}}{ }^{2+} \\
2 \mathrm{NO}_{2}+\mathrm{O}_{2}^{-}+\mathrm{e}^{-} \text {(c.b.) } \leftrightarrow 2 \mathrm{NO}_{3}{ }^{-}
\end{gathered}
$$




$$
\begin{gathered}
2 \mathrm{NO}_{2}+\mathrm{O}_{2}^{-}+\mathrm{V}_{\mathrm{O}}^{+} \text {(c.b.) } \leftrightarrow 2 \mathrm{NO}_{3}^{-}+\mathrm{V}_{\mathrm{O}}^{+} \\
\mathrm{NO}_{2}+\mathrm{O}^{-} \leftrightarrow \mathrm{NO}_{3}^{-}
\end{gathered}
$$

In surface reactions (4) to (7), electrons from the conduction band (c.b.) are trapped when surface species are formed, but not in reaction (8). If nitrates are formed by the last mechanism, a further equilibrium has to be considered, that is to say $\mathrm{NO}^{3-}$ dissociation (Equations (9)-(10)):

$$
\begin{gathered}
\mathrm{NO}_{3}{ }^{-}+\mathrm{e}^{-} \text {(c.b.) } \leftrightarrow \mathrm{NO}+2 \mathrm{O}^{-} \\
\mathrm{NO}_{3}{ }^{-}+\mathrm{V}_{\mathrm{O}}{ }^{+} \leftrightarrow \mathrm{NO}+2 \mathrm{O}^{-}+\mathrm{V}_{\mathrm{O}}{ }^{2+}
\end{gathered}
$$

when $\mathrm{O}^{-}$pressure increases, the resistance of the material also increases in an n-type semiconductor, as experimentally observed.

\section{Conclusions}

Ba-doped hematite were investigated as $\mathrm{NO}_{2}$ sensing materials. Electrical characterizations were performed by ac impedance spectroscopy under various temperatures and gas atmospheres.

Pure hematite, 3 wt \% and 4 wt \% barium-doped hematite exhibit an intrinsic semiconducting behavior. They also show a poor $\mathrm{NO}_{2}$ sensitivity. 5, 10 and $14 \mathrm{wt} \%$ barium-doped hematite exhibit an n-type extrinsic semiconducting behavior.

They are also good candidates for $\mathrm{NO}_{2}$ detection. The nitrogen dioxide sensitivity increases with the barium hexaferrite content in the material. Finally, the best compromise regarding the highest $\mathrm{NO}_{2}$ sensitivity with the lowest humidity interference is the $5 \mathrm{wt} \%$ barium-doped hematite.

The electrical study also underlines a percolation threshold of the barium hexaferrite crystalline phase in the hematite matrix. The value was estimated to $36 \mathrm{wt} \%$ barium hexaferrite.

\section{Acknowledgments}

C. Baroni is grateful to Piedmont Region for partial financial support of her Ph.D grant, to INSTM (Inter-University National Consortium on Material Science and Technology), Italy and to the Italian Ministry of Foreign Affairs in collaboration with French Government.

\section{Conflicts of Interest}

The authors declare no conflict of interest.

\section{References}

1. The European Parliament and the Council of the European Union. Directive 2008/50/EC of the European Parliament and of the Council of 21 May 2008 on ambient air quality and cleaner air for Europe. Available online: http://eur-lex.europa.eu/LexUriServ/LexUriServ.do?uri=OJ:L: 2008:152:0001:0044:EN:PDF (accessed on 22 September 2013). 
2. The European Commission. Laying down rules for Directives 2004/107/EC and 2008/50/EC of the European Parliament and of the Council as regards the reciprocal exchange of information and reporting on ambient air quality. Available online: http://eur-lex.europa.eu/LexUriServ/ LexUriServ.do?uri=OJ:L:2011:335:0086:0106:EN:PDF (accessed on 22 September 2013).

3. Kanan, S.M.; El-Kadri, O.M.; Abu-Yousef, I.A.; Kanan, M.C. Semiconducting metal oxide based sensors for selective gas pollutant detection. Sensors 2009, 9, 8158-8196.

4. Ivanov, P.; Hubalek, J.; Malysz, K.; Prášek, J.; Vilanova, X.; Llobet, E.; Correig, X. A route toward more selective and less humidity sensitive screen-printed $\mathrm{SnO}_{2}$ and $\mathrm{WO}_{3}$ gas sensitive layers. Sens. Actuators Chem. 2004, 100, 221-227.

5. Chung, Y.K.; Kim, M.H.; Um, W.S.; Lee, H.S.; Song, J.K.; Choi, S.C.; Yi, K.M.; Lee, M.J.; Chung, K.W. Gas sensing properties of $\mathrm{WO}_{3}$ thick film for $\mathrm{NO}_{2}$ gas dependent on process condition. Sens. Actuators Chem. 1999, 60, 49-56.

6. Lee, D.S.; Han, S.D.; Huh, J.S.; Lee, D.D. Nitrogen oxides-sensing characteristics of $\mathrm{WO}_{3}$-based nanocrystalline thick film gas sensor. Sens. Actuators Chem. 1999, 60, 57-63.

7. Ismail, B.; Abaab, M.; Rezig, B. Structural and electrical properties of $\mathrm{ZnO}$ films prepared by screen printing technique. Thin Solid Film. 2001, 383, 92-94.

8. Yasushi, Y.; Katsuji, Y.; Yumi, M.; Masami, O. A Thick-film $\mathrm{NO}_{2}$ sensor fabricated using Zn-Sn-Sb-O composite material. Jpn. J. Appl. Phys. 2003, 42, 7594-7598.

9. Coppedè, N.; Villani, M.; Mosca, R.; Iannotta, S.; Zappettini, A.; Calestani, D. Low temperature sensing properties of a nano hybrid material based on $\mathrm{ZnO}$ nanotetrapods and titanyl phthalocyanine. Sensors 2013, 13, 3445-3453.

10. Tonezzer, M.; Hieu, N.V. Size-dependent response of single-nanowire gas sensors. Sens. Actuators Chem. 2012, 163, 146-152.

11. Ando, M.; Steffes, H.; Chabicovsky, R.; Haruta, M.; Stangl, G. Optical and electrical $\mathrm{H}_{2^{-}}$and $\mathrm{NO}_{2}$-sensing properties of $\mathrm{Au} / \mathrm{In} x \mathrm{O} y \mathrm{~N} z$ films. IEEE Sens. J. 2004, 4, 232-236.

12. Sberveglieri, G.; Benussi, P.; Coccoli, G.; Groppelli, S.; Nelli, P. Reactively sputtered indium tin oxide polycrystalline thin films as $\mathrm{NO}$ and $\mathrm{NO}_{2}$ gas sensors. Thin Solid Film. 1990, 186, 349-360.

13. Siciliano, T.; Giulio, M.D.; Tepore, M.; Filippo, E.; Micocci, G.; Tepore, A. Room temperature $\mathrm{NO}_{2}$ sensing properties of reactivity sputtered $\mathrm{TeO}_{2}$ thin films. Sens. Actuators Chem. 2009, 137, 644-648.

14. Suehiro, J.; Zhou, G.; Imakiire, H.; Ding, W.; Hara, M. Controlled fabrication of carbon nanotube $\mathrm{NO}_{2}$ gas sensor using dielectrophoretic impedance measurement. Sens. Actuators Chem. 2005, $108,398-403$.

15. Zhuiykov, S.; Ono, T.; Yamazoe, N.; Miura, N. High-temperature $\mathrm{NO}_{x}$ sensors using zirconia solid electrolyte and zinc-family oxide sensing electrode. Solid State Ion. 2002, 152-153, 801-807.

16. Sun, H.T.; Cantalini, C.; Faccio, M.; Pelino, M. $\mathrm{NO}_{2}$ gas sensitivity of sol-gel-derived $\alpha-\mathrm{Fe}_{2} \mathrm{O}_{3}$ thin films. Thin Solid Film. 1995, 269, 97-101.

17. Cantalini, C.; Sun, H.T.; Faccio, M.; Ferri, G.; Pelino, M. Niobium-doped $\alpha-\mathrm{Fe}_{2} \mathrm{O}_{3}$ semiconductor ceramic sensors for the measurement of nitric oxide gases. Sens. Actuators Chem. 1995, 25, 673-677.

18. Tulliani, J.-M.; Baroni, C.; Lopez, C.; Dessemond, L. New NOx sensors based on hematite doped with alkaline and alkaline-earth elements. J. Eur. Ceram. Soc. 2011, 31, 2357-2364. 
19. Korotcenkov, G. Metal oxides for solid-state gas sensors: What determines our choice? Mater. Sci. Eng. 2007, 139, 1-23.

20. Barsan, N.; Weimar, U. Understanding the fundamental principles of metal oxide based gas sensors; the example of $\mathrm{CO}$ sensing with $\mathrm{SnO}_{2}$ sensors in the presence of humidity. J. Phys. Condens. Matter 2003, 15, R813-R839.

21. Tulliani, J.M.; Bonville, P. Influence of the dopants on the electrical resistance of hematite-based humidity sensors. Ceram. Int. 2005, 31, 507-514.

22. Esteban-Cubillo, A.; Tulliani, J.M.; Pecharromán, C.; Moya, J.S. Iron-oxide nanoparticles supported on sepiolite as a novel humidity sensor. J. Eur. Ceram. Soc. 2007, 27, 1983-1989.

23. Nenov, T.G.; Yordanov, S.P. Ceramic Sensor: Technology and Applications; CRC PressTechnomic Publishing Company, Inc.: Lancaster, PA, USA, 1996.

24. Traversa, E.; Ceramic sensors for humidity detection: the state-of-the-art and future developments. Sens. Actuators Chem. 1995, 23, 135-156.

25. Traversa, E.; Bearzotti, A. Humidity sensitive electrical properties of dense $\mathrm{ZnO}$ with non-ohmic electrode. J. Ceram. Soc. Jpn. 1995, 103, 11-15.

26. Santilli, C.V.; Bonnet, J.P.; Dordor, P.; Onillion, M.; Hagenmuller, P. Influence of structural defects on the electrical properties of $\alpha-\mathrm{Fe}_{2} \mathrm{O}_{3}$ ceramics. Ceram. Int. 1990, 16, 25-32.

27. Kim, K.H.; Lee, S.H.; Choi, J.S. Electrical conductivity of pure and doped $\alpha$-ferric oxides. J. Phys. Chem. Solids 1985, 46, 331-338.

28. Gardner, R.F.G.; Sweett, F.; Tanner, D.W. The electrical properties of alpha ferric oxide-II. Ferric oxide of high purity. J. Phys. Chem. Solids 1963, 24, 1183-1196.

29. Chang, R.H.; Wagner, J.B. Direct-current conductivity and iron tracer diffusion in hematite at high temperatures. J. Am. Ceram. Soc. 1972, 55, 211-213.

30. Stone, H.E.N. Electrical conductivity and sintering in iron oxides at high temperatures. J. Mater. Sci. 1968, 3, 321-325.

31. Han, J.S.; Davey, D.E.; Mulcahy, D.E.; Yu, A.B. Effect of $\mathrm{pH}$ value of the precipitation solution on the $\mathrm{CO}$ sensitivity of $\alpha-\mathrm{Fe}_{2} \mathrm{O}_{3}$. Sens. Actuators Chem. 1999, 61, 83-91.

32. Ivanovskaya, M.; Gurlo, A.; Bogdanov, P. Mechanism of $\mathrm{O}_{3}$ and $\mathrm{NO}_{2}$ detection and selectivity of the $\mathrm{In}_{2} \mathrm{O}_{3}$ sensors. Sens. Actuators Chem. 2001, 77, 264-267.

33. Liu, Z.; Ge, Y.; Tan, J.; He, C.; Shah, A.N.; Ding, Y.; Yu, L.; Zhao, W. Impacts of continuously regenerating trap and particle oxidation catalyst on the $\mathrm{NO}_{2}$ and particulate matter emissions emitted from diesel engine. J. Environ. Sci. 2012, 24, 624-631.

34. Liu, Z.; Shah, A.N.; Ge, D.Y.; Tan, J.; Jiang, L.; Yu, L.; Zhao, W.; Wang, C.; Zeng, T. Effects of continuously regenerating diesel particulate filters on regulated emissions and number-size distribution of particles emitted from a diesel engine, J. Environ. Sci. 2011, 23, 798-807.

35. Aono, H.; Hirazawa, H.; Naohara, T.; Maehara, T. Surface study of fine $\mathrm{MgFe}_{2} \mathrm{O}_{4}$ ferrite powder prepared by chemical methods. Appl. Surf. Sci. 2008, 254, 2319-2324.

36. Berger, O.; Hoffmann, T.; Fischer, W.-J.; Melev, V. Tungsten-oxide thin films as a novel materials with high sensitivity to $\mathrm{NO}_{2}, \mathrm{O}_{3}$, and $\mathrm{H}_{2} \mathrm{~S}$. Part II: Application as gas sensors. J. Mater. Sci. Mater. Electron. 2004, 15, 483-493. 
37. Chiorino, A.; Ghiotti, G.; Prinetto, F.; Carotta, M.C.; Gnani, D.; Martinelli, G. Preparation and characterization of $\mathrm{SnO}_{2}$ and $\mathrm{MoO}_{x}-\mathrm{SnO}$ nanosized powders for thick film gas sensors. Sens. Actuators Chem. 1999, 58, 338-349.

(C) 2013 by the authors; licensee MDPI, Basel, Switzerland. This article is an open access article distributed under the terms and conditions of the Creative Commons Attribution license (http://creativecommons.org/licenses/by/3.0/). 